\title{
CES
}

COOPERATIVISMO E ECONOMÍA SOCIAL

Núm. 43 (2020-2021), páxs. 361-365

ISSN: 2660-6348

\section{ECONOMÍA SOCIAL Y SOLIDARIA Y GÉNERO. APORTES TRANSDISCIPLINARIOS DESDE EUROPA Y LATINOAMÉRICA, VALENCIA, TIRANT LO BLANCH, 2020 (DIRS. DICAPUA, M.A./ SENENT VIDAL, M.J./FAJARDO GARCÍA, G.)}

Amalia RodríGUez GonZÁleZ*

1 Profesora Titular de Derecho Mercantil, Universidad de Valladolid, amalia.rodriguez@uva.es. Dirección postal: C/Plaza de Santa Cruz, 8, 47002 Valladolid, España. 


1 libro que ahora tenemos la satisfacción de recensionar, está prorrogado por la prof ${ }^{a}$ Dra. I. GEMMA FAJARDO GARCÍA y tiene origen en el proyecto de investigación: Economía Social, Autogestión y Empleo (DER2016-78732-R) promovido desde el Instituto de Investigación en Economía Social, Cooperativismo y Emprendimiento (IUDESCOOP) de la Universidad de Valencia, y financiado por el Ministerio de Ciencia, Innovación y Universidades, la Agencia Estatal de Investigación y el Fondo Europeo de Desarrollo Regional (FEDER), proyecto del que ha sido investigadora principal la profesora Fajardo.

El trabajo colectivo dirigido por las profesoras DICAPUA, SENENT y FAJARDO, reúne en torno al tema de la economía social y solidaria y la igualdad de género a expertos y expertas de diferentes universidades y países (España, Grecia, Portugal, Argentina, Colombia, Brasil, Paraguay Venezuela y Uruguay) en diferentes áreas de conocimiento, lo que enriquece aún más el libro. En su conjunto, presenta veintiuna aportaciones de treinta y nueve personas investigadoras expertas de la práctica en el sector, con una inequívoca vocación internacional e interdisciplinar y un gran esfuerzo por parte de sus directoras, a la hora de sistematizar los trabajos en una monografía de gran calidad. El libro nos parece de especial importancia y actualidad puesto que, además, no hay estudios monográficos actualizados en estas materias abordadas de forma conjunta.

Desde el punto de vista sistemático, esta monografía comienza con la introducción que realizan las profesoras Senent y Dicapua y en ella se pone de manifiesto la preocupación constante por el debate sobre el género y las practicas solidarias en la economia social. El libro pretende sistematizar los resultados y la conclusiones que se derivan de las aportaciones doctrinales que se realizan y que suponen un avance en la cuestión, ya que los postulados que aquí se desarrollan aportan innovaciones en la Doctrina al abordar la materia, como una eficaz herramienta para las empresas a la hora de dar respuesta a buenas prácticas en materia de igualdad de género dentro de sus organizaciones, así como la relevancia de los programas y medidas de políticas publica para ponerlos en marcha y fomentarlos.

Como bien indican las directoras en la Introducción, las partes en la que se estructura el trabajo, dan cuenta de los principales ejes desde los cuales puede discutirse la equidad de género. Así, se divide en cuatro grandes apartados. El primero de ellos: “¿Es posible pensar la economía social y solidaria desde la problemática de género?”. Esta primera parte está formada por los trabajos de seis investigadoras. El primero de ellos de MARÍA ATIENZA DE ANDRÉS que desarrolla: "La necesaria incorporación de la perspectiva feminista en el momento de despliegue actual de la Economía Solidaria". El segundo se dedica a analizar: "Factores de atracción para el emprendimiento cooperativo femenino. Análisis del microemprendimiento en Galicia" y está firmado por MARÍA BASTIDA DOMÍNGUEZ, 
ANA OLVEIRA BLANCO y MARIA TERESA CANCELO MÁRQUEZ. El tercero de los trabajos escrito por BEATRIZ CALDERÓN MILÁN y MARIA JOSÉ CALDERÓN MILÁN se plantea la siguiente cuestión: “¿Son las entidades de economía social más sensibles a la igualdad de género? Un análisis de las trayectorias laborales de las mujeres en puestos de alta cualificación". El cuarto de los artículos lleva por título: "Women in Solidarity Economy in Greece: Liberation Practices or One More Task Undertaken by Women?", escrito por IRENE SOTIROPOULOU. El análisis de las "Diferencias de género en las cooperativas de trabajo asociado españolas" ha sido escrito por MARÍA DEL CARMEN PÉREZ GONZÁLEZ y LIDIA VALIENTE PALMA. Y el último artículo de esta primera parte lleva por título: “¿Es la economía social y solidaria una habitación propia para el empoderamiento de las mujeres? Reflexiones sobre una epistemología feminista y descolonial para su estudio desde una sociología de la emergencia", se ha desarrollado por ROSANA MONTALBÁN MOYA.

La segunda parte: "Genero y economía social/solidaria desde la perspectiva del Derecho", está compuesta por cuatro aportaciones. La primera: "Algunas consideraciones sobre el artículo 13 de la Ley de sociedades laborales (promoción de la igualdad de oportunidades como deber específico de los administradores)" está firmado por AMALIA RODRÍGUEZ GONZÁLEZY SOLEDAD FERNÁNDEZ SAHAGÚN. El segundo es de MARCELA ACHINELLI BÁEZ, MARÍA DE LOS ÁNGELES DI CAPUA y ANA LETICIA CAROSINI y lleva a cabo un estudio de casos: "Aportes de la economía feminista a la economía social: la conciliación laboral y familiar en las Cooperativas de Ahorro y Crédito de Asunción, Paraguay. Periodo 1994-2014".

El tercer trabajo lleva por título: "Perspectiva de género en marcos legales de la ESS. El caso del proyecto de ley de la provincia de Santa Fe" de LUCIANA SOSA, y, por último, MARÍA DEL PINO DOMÍNGUEZ CABRERA realiza: "La indagación jurídica de la equidad de género en las empresas de economía social en la Comunidad Autónoma Canaria".

La tercera parte: "La transversalidad de género en la organización interna y las políticas públicas en la economía social/solidaria", incorpora seis artículos. El primero de ellos: "El techo de cristal en cooperativas multiactivas en Colombia" está firmado por ELIZABETH OVIEDO, NORBERTO PORTELLA ANGARITA y MARTHA ROCÍO GODOY RODRÍGUEZ.

El segundo, "Del trabajo al trabajo de la casa. Un análisis de la implementación del subprograma «Ellas hacen»", está firmado por AGUSTÍN TORRES Y CECILIA MELÉNDEZ. El tercero ha sido redactado por MARTA SÁNCHEZ MIÑARRO y lleva por título: "Mujeres, economía y emancipación. Empoderamiento y equidad de género en la economía social y solidaria". La autoría de: "Trabajo, familia y cuidados. Abordando su articulación en una experiencia cooperativa" pertenece a LUISINA LOGIODICE y ANDREA DELFINO. El siguien- 
te trabajo de esta tercera parte ha sido escrito por DEOLINDA MEIRA Y ANA LUÍSA MARTINHO y se dedica al estudio de: "A participaçâo das mulheres nas cooperativas portuguesas-Que caminos para a paridade?"; finalmente, BEATRIZ CARRASCOSA VON GLEHN SCHWENK y EDNALVA FELIX DAS NEVES han redactado el artículo. "Tem rapadura pura": reflexôes sobre o mundo do trabalho das mulheres negras, desigualdades e resistencias".

La cuarta parte de la publicación colectiva: "Economía social/solidaria y género desde los discursos y las prácticas sociales y políticas de las mujeres" está compuesto por cinco capítulos. El primero de ellos: "Yo lo único que sé es militar la cooperativa. La Economía Social desde la mirada de género", está escrito por Lucrecia Saltzmann. El segundo de ANABEL RIEIRO CASTIÑEIRA y LUCÍA PÉREZ CHABANEAU lleva por título: "La otra economía en Uruguay: una mirada desde la solidaridad y el feminismo". El siguiente trabajo es: "Mujeres, autogestión y solidaridad: reflexiones sobre la construcción de procesos autogestivos en la ciudad de Paraná (Provincia de Entre Ríos, Argentina)" cuyas autoras son MARIELA ISABEL HERRERA, DAIANA PÉREZ, PAULA ANDREA ROSES Y SALÓME VUARANT. Le sigue: "La equidad de género narrada por cooperativistas feministas y situada en la economía social y solidaria madrileña", de Alicia Rius Buitrago y, finalmente: "Mujeres cooperativistas en Mérida, Venezuela: desde una visión etnográfica", ha sido redactado por CARMEN ROSILLO y BENITO DÍAZ.

El libro colectivo presenta un indudable interés, y constituye un trabajo de referencia quienes quieran profundizar y actualizar sus conocimientos en estas materias. 